\title{
Issues on E-health Adoption in Nigeria
}

\author{
Kolawole J. Adebayo \\ Southwestern University/ Dept. of Computer Science, Okun-Owa, Ijebu-Ode, Nigeria \\ Email: collawolley3@yahoo.com \\ Edward O. Ofoegbu \\ Oduduwa University/ Dept. of Computer Science, Ipetumodu, Ile-Ife, Nigeria \\ Email: edoxnt@yahoo.com
}

\begin{abstract}
E-health is the application of information technology for health care management. It includes all applications of information communication technologies to promote healthcare services support, delivery and education for improving efficiency in health care delivery to the citizens. Many factors contribute to the poor state of the medical sector of Nigeria, and in fact many developing countries, two of the most important being record keeping and accessibility. Nigeria still operates a paper based healthcare delivery system; meeting demands of citizens have been increasingly difficult due to her huge population, understaffed hospitals, apathy towards embracing ICTs and other issues. On the other hand, ICT applications have been used successfully in developed countries to address most of these problems. This paper presents an in-depth analysis of the healthcare system in Nigeria while highlighting confronting issues with a view to proposing a viable solution.
\end{abstract}

Index Terms-E-Health, Electronics Health Record (EHR), Primary Health Care (PHC).

\section{INTRODUCTION}

Health is wealth, says the common slogan. Healthcare spans across all ages, genders, races, culture and geographical boundaries and is an area of concern to all population. Many countries (especially developing countries) are plagued with critical healthcare issues such as infectious and/or pandemic diseases, a lack of basic healthcare programmes and facilities and a shortage of skilled healthcare workers [1][2]. The authors in [1] opined that poor healthcare obstructs prosperity and business profitability, and does not help reduce poverty. More importantly, it directly affects the mortality levels of the people living in these countries. Therefore, proper management of healthcare is a prime concern for the development of all developing countries.

Electronic Health (E-Health) facilitates healthcare to reach remote population which are not properly serviced by traditional means. E-Health has been defined as an amalgamation of healthcare system and Information Communication Technology (ICT) to enable better health and healthcare delivery [3]. According to Silber [5], EHealth is an "application of information and communication technologies (ICT) across the whole range of functions that affect health". It is also an emerging field in the intersection of medical informatics, public health and business, and refers to health services and information delivered or enhanced through the Internet and related technologies [4]. E-health kicks off a revolution to traditionally paper-based healthcare system for improved efficiency in healthcare delivery which is triggered by citizen/customer's demand, increasing cost of medical treatments, and the availability of information technologies to implement e-healthcare services. Over the years, E-health applications have demonstrated its ability in bringing huge benefits in terms of making healthcare available to all citizens at the best cost. Since the effectiveness of a country's health care delivery system is central in meeting its health goals, the Nigerian health care system with respect to development, facility, accesibility and operational implementation have not been able to live up to expectations and has thus performed dismally especially when compared with lesser endowed African countries. To capture the importance of e-health adoption to a country's growth and development, countries such has South Africa has rolled out robust e-health development strategy [6] which shows the path path the country aims to tow in achieveing total healthcare delivery and providing long and healthy life for the citizens.

The Nigerian healthcare system called the national health system is decentralized into a three tier structure with responsibilities at the federal, state and local government levels with currently all three tiers being involved to some extent in all major health system functions which includes stewardship, financing and service provision. It is a known fact that the overall health of a nation is highly dependent on the efficient and successful implementation of primary health care services or community level delivery. To this end the 1988 National Health Policy included the creation of the primary health care (PHC) management. This is well conceived and especially needed and to improve the delivery of primary health care services in the country since a large percentage of the citizenry lives in rural to semi-urban settlements. As E-health systems are capable of ensuring cost optimization especially in a period of global economic crisis as it is presently the case, while being able to deliver on its basic functionaliy responsiblities such as supporting the financial aspects of healthcare and ensuring that all treatment providers are 
well paid while patients spends only what they are due to spend according to their insurance policies; it becomes imperative for E-Health system adoption to be taken seriously and not overlooked as it presents an holistic solution to the problems ravaging the Nigeria healthcare sector.

E-Health system have been implemented in most countries in Europe with European governments setting up combined systems of health insurance in which public compulsory health insurance coexists with private companies. Several countries in Europe such as France, where the GIE SESAM-Vitale was created by the partners of the French Health Insurance to develop common solutions to meet the needs of all its members, whether they are part of the compulsory systems or the complementary insurance organizations and combined with Caisse Nationale d'Assurance Maladie- Travailleurs Salariés (CNAM-TS - National Health Insurance) which itself is in charge of the management of the general scheme of health insurance to form the composite insurance cover for the users of the E-Health system.

In the French system, Healthcare professionals are represented through Orders, such as the Ordre National des Médecins (National Order of Doctors), Ordre National des Pharmaciens (National Order of Pharmacists) and others. The Orders represent healthcare professionals in their negotiations with other stakeholders, and thus takes responsibility in the implementation of some projects. Healthcare professionals benefit from subsidies to support their equipment cost for e-Health terminals while the Patients in this scheme are free to choose which healthcare professional they want to deal with while allowing them also choose their mutual or private insurance.

In Germany the Gematik originally "Gesellschaft fu $\square \mathrm{r}$ Telematik" (Company for telematics) which is a common structure owned $50 \%$ by healthcare providers (doctors, pharmacists, hospitals) and $50 \%$ by payers (Statutory Health Insurance Funds Association and the Association of Private Health Insurance). Gematik, under the legal supervision of the Federal Ministry of Health performs various tasks in the implementation of the health card and telematics infrastructure. Gematik focuses on three core competencies which are designing, permitting and operational responsibility. The German government has introduced electronic Health Cards (electronische Gesundheits-karte or eGK) for all insured citizens. The electronic chip in these smart cards contains personal data, insurance details and medical history records. German health insurance companies issue electronic Health Cards (eGK) to patients insured by them and this card is used by the cardholders, when they use health care services, which are covered by the insurance.

The OBAMACARE is also an E-Health initiative being proposed by the Obama administration of the USA to ensure quality health care for its citizens. Based on the successes of these systems in their respective countries and their recorded improvement of health care delivery system, it is our believe that the improvement can be replicated in Nigeria by adopting and implementing a robust and custom built E-Health infrastructure that will be tailored to the specific needs of the country while taking cognizance of our unique nature. This is necessary as the country is in dire need of reforms in its health care services sector if we are to so as to improve the health state of citizens.

The remainder of this paper is organized as follows: In section 2, we reviewed some related works; this is followed by section 3 which describes the adopted research approach. Section 4 gives the findings, evaluations and recommendations. The final section contains the conclusion.

\section{RELATED WORKS}

Reference [7] enumerated on Nigeria's dismal performance in her health care service delivery as well as her funding of the health sector. Comparisons with less endowed countries like Uganda were carried out which reveals Uganda allocates $11 \%$ of its total budget to health care while Nigeria allocates a meager $5.5 \%$ of its own budget. The study goes on to state that despite the high $\mathrm{HIV}+$ patients in Uganda the country was ranked 149 out of 191 countries and came 39 steps above Nigeria in the World Health Report 2000 rankings. The above amongst others goes to show the state of the Nigerian health care system with clear indication of problems areas such as inadequate funding which itself is a perquisite for any meaningful undertaking in any health policy.

Denise [8] enumerated the significance of e-healthcare adoption in developing countries. In his work, several benefits such system promotes were presented for total advancement of ICT use in the healthcare sector. His work was complemented by Drury P. [9] who in his work developed a model for e-health systems in the developing world.

The author in [10] pushed for a reform of the Nigerian health sector. He opined that the systems currently in use were no longer working or producing the optimal health status possible and deserved by the people as indicated in the 2000 World Health Report where Nigeria ranked as the 187 th of the 191 member nations ranked for health systems performance. Clear emphasis was placed on improvement in primary healthcare service as it contributes a great deal to quality health care delivery.

The author in [11] examined the problems of quality healthcare and accessibility to healthcare. The study stated that the problems with quality in healthcare can be revealed on evaluation of the adequacy of healthcare facilities and systems. This evaluation yardstick includes healthcare policies at medical centers, adequacy of standard operating procedures at these centers, adequacy of the level and scope of care by the physicians and the nurses in light of current knowledge and accepted standards of medical practice in the medical world and problems with accessibility to care would include evaluation of the adequacy of the numbers of healthcare facilities and the proper distribution of these facilities to allow easy and immediate access to a medical facility for 
every patient who needs one. By the assessment of the author for quality healthcare delivery, it becomes pertinent to find a suitable system or methodology that can solve the two problems enumerated above in a cost effective way while delivering quality.

\section{RESEARCH METHODOLOGY}

Bringing information technologies to healthcare systems encompasses a variety of applications, in tune with needs, both on an individual basis and on a society level. Information technology increases the efficiency of the administrative processes while optimizing costs by rendering all information flows that were previously based on paper documents and translating it into an electronic. Thus an E-Health system implementable in a country like Nigeria must bring convenience for all its stakeholders and must also include security features. For this reason, security procedures commonly found in payment systems, or in company security systems are implemented as these systems ensure Confidentiality, Identification, Authentication, Digital signatures and Transaction management. To ensure these objectives are fulfilled a national e-Health system will very often use smart cards carrying the patient or healthcare professional's identity and thus achieve the security needs of e-Health applications thanks to a dedicated security layer infrastructure. The e-health system network can be described as shown in fig 1 below with its four accompanying elements which forms the fulcrum on which any e-health system is built. These elements are briefly described as follows

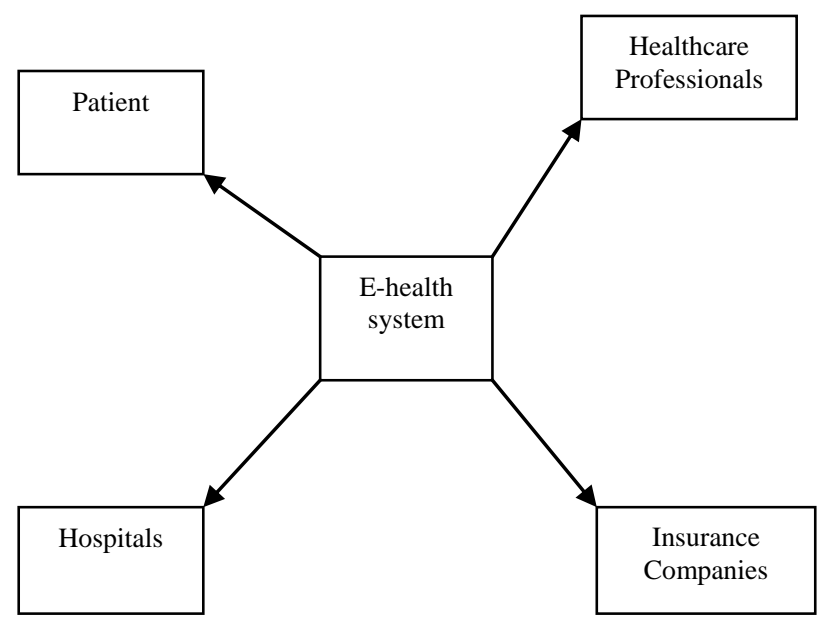

Fig 1: An E-Health Solution Infrastructure

\section{A. The Patient}

The patient typically demands the best healthcare service at a minimal cost and involvement in the administrative processes. For this reason, patients would be entitled to a health card that will guarantee them access to healthcare as well as managing the administrative and payment/reimbursement aspects.
Patients in other countries with an E-Health system are generally happier to have their medical expenses paid directly by public and private insurances rather than to have to pay for medical expenses upfront, and later to be reimbursed. Such a system is therefore recommended for patients in Nigeria even though other systems of payment could still be used such as Mobile money or online payments. Since the Health card is used to carry patient rights, the healthcare IT infrastructure has to take into account card issuance along with options for the patient to read his card and to update it. The medical system has to include some medical data and ensure this access is kept confidential, i.e. reserved to the patient and authorized healthcare professionals. Patients must be given a means to access this medical data and to achieve this in a secure manner; the patient health card is used as an authentication means to give access to patient healthcare related data. In some cases, both the patient and the healthcare professional card could be combined to ensure only the healthcare professionals authorized by the patient have access to the data.

\section{B. The Healthcare Professional}

Healthcare professionals include many medical practitioners who have different relations with patients, these includes Doctors, Pharmacists, Nurses, Midwives and physiotherapists. As most healthcare professionals prefer to concentrate on delivering a treatment than on administrative chores and the administrative part of the system has to adapt to medical practice in a seamless and effortless manner. To perform these administrative tasks, healthcare professionals must get equipped with IT equipment such as computers, healthcare card terminals, communication means, printers etc.

\section{The Hospital}

Hospital administrative data should be managed on databases and traditional IT systems with access to this data restricted to the administrative personnel only. Eprescription should also be employed so that the prescription given out by a doctor is no longer on paper, but is either written on the patient card, or stored over a network (or in the cloud), and the patient card will be used as the secure key to gain access to it when the pharmacist delivers medicines. Making prescriptions the electronic way helps combat fraud and reduce errors with better information shared between professionals that can also be combined with a server side process detecting interactions between several treatments delivered by various doctors. Patient data confidentiality should be incorporated in the system as a primary concern since patient information is a confidential issue the E-health system must address. Also, means must be developed for secure transfer of patient data by healthcare practitioners who feel the need to share information with their peers. Medical records are managed separately from administrative data for privacy and security reasons. In most cases, in hospitals, medical records are managed on databases using traditional IT systems. As medical records are especially sensitive, security procedures 
should be in place to restrict access to this data. The healthcare card should be used as a means to access emedical records and in order to ensure data confidentiality and security, data communication should be kept under close control with data encrypted, and signed using the healthcare card as a signature and cryptographic keys container.

\section{The Insurance Systems}

The goal of a public insurance system is to execute government policies. In other words, the public insurance system is in charge of managing the financial and administrative aspects of the system, aiming to monitor the delivery of the best possible healthcare services, for a given cost. Public insurance systems like the National Health Insurance Scheme (NHIS) aims at ensuring a smooth and efficient data flow to complete payments to all stakeholders especially with subsidized rates for drugs. Standard public insurance systems are in charge of managing the relation with insured people, or in other words, all (or most) citizens, which generally takes the form either of a health card or of an e-health application on an existing national ID card.

Since public insurance bodies are answerable to governments and in a more general sense to the citizens, they have to demonstrate that they can manage the healthcare organization efficiently and run a transparent and auditable system, However, there exists no better way of achieving this than through the incorporation of IT into their operations. Private insurance companies, whether they are mutual insurance companies or commercial insurance companies also have a costefficiency objective with their main objective being to ensure easy and efficient interaction with patients, who are actually their customers. Private insurance companies should have a permanent relationship with healthcare professionals and must ensure this relationship is managed in an efficient manner. Private insurance companies sometimes establish an affiliation program with a selection of healthcare professionals, directing patients to them with the compensation of limiting their pricing policies. As the healthcare systems all over the world often involve a combination of public and private payment, most private insurance companies have an already established relationship with the public healthcare bodies.

\section{E. Research focus}

This study presents a holistic view of issues on e-health care adoption in Nigeria. It toes the path of a reproducible research, in which a critical examination of e-health system adoption in Nigeria was done in order to project a framework for proper assessment of the current healthcare system, its flaws as well as the expectation of the citizenry and professionals on ways of solving the present problems and of course providing a leeway to a tested and robust e-health approach as has been found operational in some developed climes. It should be noted that our work is limited to verifying the availability of ICT equipment in our health facilities, presence of staffs that can handle such tools, the acceptance and use of electronic medical record (as e-medical record is a core component of e-health) and introduction of smart card for detailing patient's information and people's (health officers and patients) perception to use of such card in improving health delivery.

Nigeria is a country located in West Africa with a total area of $923,768 \mathrm{~km}^{2}$ thus making it the world's 32ndlargest country. The country is divided into thirty-six states and one Federal Capital Territory, which are further sub-divided into 774 Local Government Areas (LGAs). The states are further classified along their geographical spread into six geopolitical zones namely the North-West, North-East, North-Central, South-East, South-South, and South-West. A 2012 estimate puts the population of Nigeria at 168.8 million people up from the 140 million recorded in her 2006 population census [12]. Of this latest estimate, about 87 million people (52\%) dwell in rural areas while 81 million dwell in the urban areas [12]. Estimated figure for registered hospital nationwide stands at 4,000, excluding the 700 health care centers, 1,670 maternity centers and the 12 University Teaching Hospitals which handles tertiary care. Statistics prescribes a figure of 0.2 physicians and 1.7 hospital beds per 1,000 people.

Due to the sheer size of Nigeria, we elected to approximate our research to a sub-geographical confinement, with this; a state was focalized to properly assess e-health adoption in Nigeria. Since most states in the country with the exception of some northern states are at par in terms of infrastructural development, elite citizenship and educational appraisal, we decided on choosing an agrarian state which has a middle - to - high level infrastructural development to carry out the research, we believe this state gives us a statistical balance to accurately project our findings in terms of Nigeria as a whole. Building on this premise, Oyo state was used as our research base. We believe our choice of Oyo state is appropriate since population density is considerable and most people are deprived of adequate healthcare facilities. Also the state has a reasonable population of educated citizen with a blend of urban and rural life as well as being home to three university teaching hospitals (University of Ibadan teaching hospital UCH, LAUTECH teaching hospital as well as BOWEN university teaching hospital) evenly spread among the tribal blocks in the state. We believe these institutions can be used as a launch pad for the proposed scheme. For this reason, medical professional including doctors and pharmacist of both registered private hospitals and public rural primary health centre, maternity homes and state hospitals resident in towns as well ordinary citizens including the rural dwellers and urban settlers from different cities and towns of the state have been selected to complete the survey for the research work. It's essential to have the medical personnel's and patients' views relating to the proposed and existing system to find the possibilities of introducing it for the improvement of better healthcare system. All the required information about the study area was obtained by preliminary field investigation. Simple 
random sampling procedure was used for the research. Primary data was collected using the interviews of the respondents from the study area.

The methods of data collection were interview, survey and questionnaire. Furthermore, we obtained some desired data from the World Health Organization (WHO) report on the current health care system of Nigeria. Available information [13] indicates that the performance of Nigeria even though has improved slightly in recent times in terms of the yearly budgetary allocation, a clear insufficiency still exists when compared with some African countries with lesser economy, for example Uganda has $11 \%$ of her total budget allocated to healthcare as of 2005 while Nigeria's 2006 budgetary health allocation stands below 6\%. We have designed some comprehensive fact revealing questionnaires for our work. The questionnaire designed is also included as annex in the paper and have been administered to volunteers (including health professionals) in order to understand their perception of the current system and possible adoption of an e-health card system.

\section{FINDINGS AND EVAlUATIONS}

The revelation from the response of the questionnaire respondents has shown a gross mismanagement of health care system in the rural areas. We discovered poor or no use of ICT facilities in the health sector of the study area. We extend our definition of poor use of ICT facilities to include lack of ICT facilities that can improve healthcare delivery in the aforementioned study area. Our study shows that the hospitals do not have proper allocation of computers, in fact, most practitioners at both private and public health centre relies on paper work. Internet facility does not even come to bear. Patient's information is kept manually. They do not maintain any modern health care information system that contains database, software application, online medical training for nurses etc. The problems in the existing healthcare systems have been found to include the following:

- Inadequacy of medical practitioners proficient in the use of ICT tools.

- Lack of centralized national healthcare database.

- Grossly deficient budgetary allocation for the health sector, including lack of proper policy formulation and implementation emanating from bureaucracy and corruption in governmental institutions.

- Poor access to basic qualitative and affordable health care services, mostly pronounced in the rural communities.

- Poor structural development and lack of maintenance culture allow waste of resources in terms of finance, equipment and human resources.

- Difficulties in medical referral system which disjoints proper follow up and avoid repetition of treatment.

- Inadequate IT facility and technology. These include lack of internet access in all or major medical facilities. Also observed is the poor computer usage and hence adoption of manual system.

These problems have generated lots of problems such as high mortality rate, increase cost of treatment, drug misuse and its attendant reactions such as disability, death, drug resistance etc.

\section{A. Questionnaire Characteristics \\ Respondents' Demographic}

The prepared questionnaires were distributed among four ethno-divisions of the state. This includes the capital city, Ibadan; Oyo, Ogbomosho and Oke-Ogun regions. In Oke-Ogun, we limited the questionnaire distribution to three major axes of the region namely, Saki, Iseyin and Oke-Iho. In all, 1327 questionnaires were returned of which 1200 was selected and found statistically usable. The result of the survey showed that the percentage of male that participated in the survey was $62 \%$ and the average age of male participants was 33.40 years. The percentage of female participants was $38 \%$ and their average age was 28.50 years with the average age observed being 30.95 years. $68 \%$ of the participants were non-specialist locals i.e. those who are not medical practitioners while the rest are specialist such as trained doctors and nurses, Internship doctors and pharmacists.

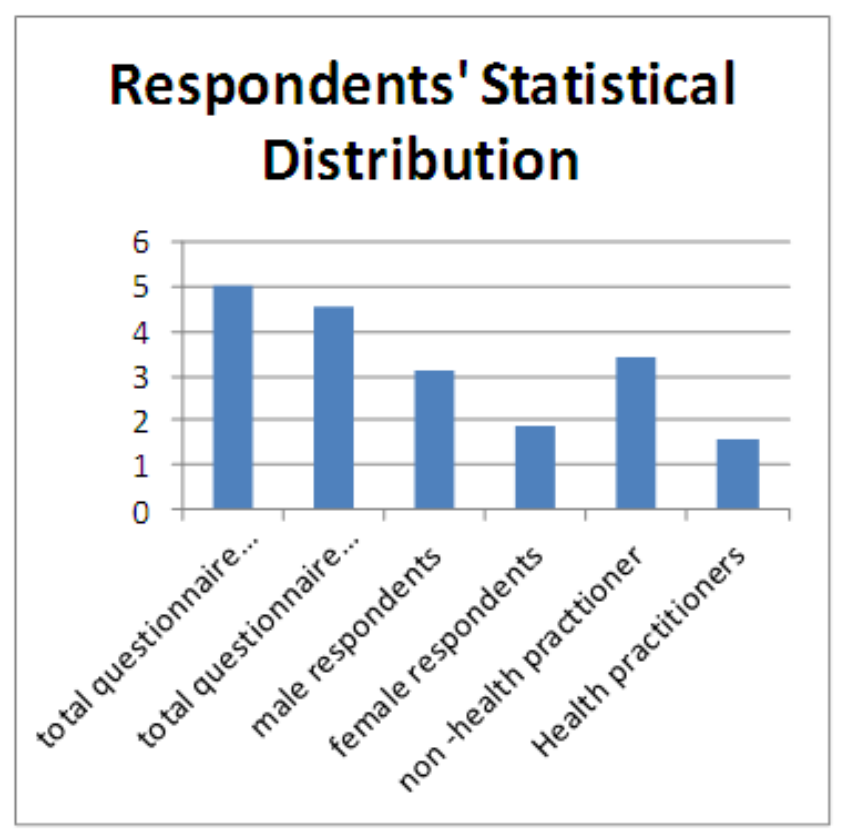

Fig 2: Chart showing Respondent's distribution

\section{B. Respondent's Complaints Analysis}

The survey pointed out common complaints among respondents which included the following: $70 \%$ of survey participants believe that the current healthcare's deficiency and inefficiency is due to poor health facilities and inadequate equipment; a further $24 \%$ blame the absence of clinics and health centers for the problems. $28 \%$ claim that poor recordkeeping and attention delay is responsible and $74 \%$ believe the persistent problems are due to incapable personnel and inadequate qualified 
practitioners. $18 \%$ attribute a portion of the problem to laziness of medical staff and lackadaisical attitude. 50\% support the motion that the rot in the country's healthcare is caused by the government's poor financing; $4 \%$ of those further state that the government does not look after its medical employees. $8 \%$ say that poor administration and distribution of drugs is one of the causes. $24 \%$ believe that inaccessibility to medical facilities is the bane. $16 \%$ attribute the problems also to ignorance, standard of living of the people and illiteracy. Also, $40 \%$ blame the corruption in Government as the major factor of the problems in the country's healthcare system.

Among the elite locals, 92\% believes the adoption and use of ICT will greatly improve the health care delivery. Our probe in the rural areas and especially to the uneducated locals shows a great indifference to e-health adoption, $82 \%$ of them however give support to its use providing it will improve health delivery to them. To our surprise, only $87 \%$ of the medical practitioners share the same view with the elite locals, of this, $44 \%$ are doctors and the others either nurses, medical laboratory technologist etc. Our surprise is premised on our expectations that medical practitioners should be at the forefront of the fight for e-health adoption in the country and hence should all have voted for an ICT driven health sector. However, we believe this is partly due to the fact that many of them may not be very comfortable with the use of computers especially those of them who are already advanced in age.

We probed the medical practitioners further just to know the wide statistical gap between theirs and the locals preferences for e-health adoption and a most important issue of power was raised, they claimed that with the epileptic power supply in the country, the whole gain of the system will brought to naught, they cited the fact that they will still have to revert to the manual system most time when there is no power supply which implies double work. Also mentioned is the issue of computer appreciation training for those not conversant with its use.

\section{E-Health Card Framework to the rescue}

The e-Health card is a Smart ID card that is small enough to fit into a wallet for easy movability. A smart ID card combines integrated circuits, which can process data. The card has the ability to receive inputs by the application and able to deliver an output. A smart ID card provides secure service to an organization to support identity based applications such as sign-on and authorization management (manages secure passwords) and has been used extensively in the financial sector e.g. credit and debit card, ATM cards etc. Ref [14] can be consulted for enlightenment on smart card technology. Mohammad and Palash [15] has prototyped an e-health card system for developing countries. The authors in [9] also implemented an electronic medical record for use in third world economies. Part of our goal in this work is to ascertain our people's disposition to the use and adoption of a system similar to the one they proposed.
Table 1: Statistic detailing Respondent's Opinion

\begin{tabular}{|c|c|c|c|}
\hline \multirow{2}{*}{$\begin{array}{c}\text { Issues militating existing } \\
\text { Healthcare system }\end{array}$} & \multicolumn{3}{|c|}{ Respondent's opinion statistic (\%) } \\
\hline & $\begin{array}{c}\text { Health } \\
\text { practitioners }\end{array}$ & $\begin{array}{l}\text { Non-Health } \\
\text { practitioners }\end{array}$ & total \\
\hline $\begin{array}{l}\text { Absence of adequate } \\
\text { clinic and health centre }\end{array}$ & 08 & 16 & 24 \\
\hline $\begin{array}{c}\text { Poor and incoherent } \\
\text { medical record keeping }\end{array}$ & 21 & 07 & 28 \\
\hline $\begin{array}{l}\text { Poor financing and } \\
\text { infrastructure provision }\end{array}$ & 31 & 19 & 50 \\
\hline $\begin{array}{l}\text { Neglect of staff by } \\
\text { government }\end{array}$ & 38 & 04 & 42 \\
\hline $\begin{array}{l}\text { Lack of staff ICT } \\
\text { competency training }\end{array}$ & 41 & 21 & 62 \\
\hline $\begin{array}{l}\text { Illiteracy and ignorance } \\
\text { on the part of patients }\end{array}$ & 12 & 04 & 16 \\
\hline corruption & 21 & 19 & 40 \\
\hline $\begin{array}{l}\text { Medical staffs deficient } \\
\text { in ICT literacy and } \\
\text { compliant }\end{array}$ & 32 & 30 & 62 \\
\hline $\begin{array}{c}\text { Instant support for e- } \\
\text { health strategies } \\
\text { deployment }\end{array}$ & 87 & 92 & \\
\hline
\end{tabular}

An e-health card is designed to contain medical history as well as doctors' prescriptions for patients. The eHealth card will provide a patient with a secure copy of the patient's personal Electronic Health Record. The system will not only help save costs and make for efficient and organized communication between doctor and patient but would also facilitate quick and secure access to data and the electronic transmission of medical information. It would also reduce the overdependence on a particular hospital as patient can use the card in any hospital with a personal digital assistant (PDA).

A patient's card can begin operation upon receiving it and may keep medical records from the moment the patient starts using it. Medical history before the point of usage (stored in voluminous handwritten notes) can still be referred to in case of importance.

In the case of emergencies, the e-Health card can contain critical information about patients in case of operations and allergic reactions. For this, medical specialist need only know the patient's name and follow an emergency mechanism implemented in the database software that only the doctor has access, this is required in order to make use of the card to find out information about the patient. This will be beneficial as it can allow the patient make use of any nearby hospital and still have their records accessible by a medical practitioner not known to the patient beforehand. 


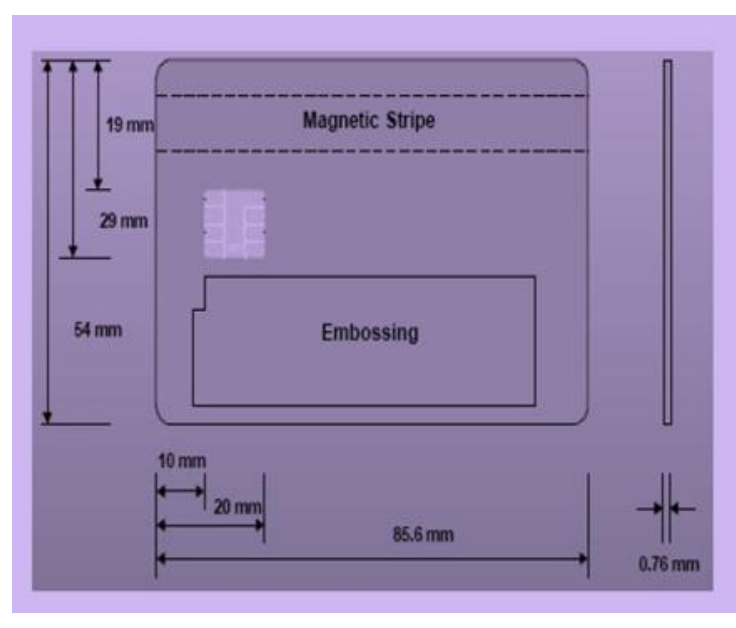

Fig 3: Schematic representation of smart card technology

As a way of ameliorating the hitherto faced problems in the sector, we set at understanding the perception of people towards the use and adoption of a grid-based unified health database powered by an e-health card system, accompanied with the questionnaire is an information piece that describes our idea of e-health card system. We specially focused on the medical practitioners who are supposed to be in the direct use of such system. We explained the benefits to be gained by adopting such a system to include patient Information portability, efficient storage of patient data, availability of patient data upon requirement, easier and faster access to patients' previous records, enhanced communication between Doctors and Patients, constant monitoring of Patient status update and situation, better diagnosis and quick administration, easy accessibility to healthcare and cheap services, patient's data confidentiality and hospitals and diagnostic synchronization, Also, we emphasized the concept of confidentiality that the system guaranteed with its multi-level security framework which even exceeds the confidentiality and security of patient's data obtainable with the existing system.

We were eager to know whether people, especially the medical practitioners already have idea about the e-health card system and will appreciate its adoption. The result of the study revealed that $42 \%$ of the participants have an idea, have heard about, and understand the concepts regarding the proposed system while $56 \%$ do not have any idea about it but understand the concept. $2 \%$ have no idea about the system and don't understand the concept. $30 \%$ of respondents believe that the system will be easy and cheap in terms of mobility and accessibility of health care systems; and also believe that the system will encourage portability of patient data rather than have bulks and voluminous ledgers and records of patient information. $57 \%$ believe that the proposed system would result in efficient storage of data. 52\% believe that the proposed system would make data stored to be readily available anytime it is called upon and anytime the medical practitioner requests for it which can help in the case of emergencies. $43 \%$ believe that the proposed system would encourage easier transaction and understanding communication between patients and doctors, even if they haven't met prior to their transaction. $14 \%$ believe that the proposed system would complement and better the country's existing healthcare structure and enable it to compete successfully with her neighbors' and other developing countries' healthcare systems. 33\% are certain it would permit reliable, secured and unadulterated patient data and it would also reduce patient's dependence on medical centers and reduce the workload on available doctors. $10 \%$ believe it would improve doctors' healthcare knowledge. Also, the study revealed that $44 \%$ don't agree that the system is necessary for the study area while $56 \%$ believe that the system would be very good and would welcome it. $30 \%$ of the respondents could not see reason on how such system could be beneficial to doctors and patients while $70 \%$ disagreed.

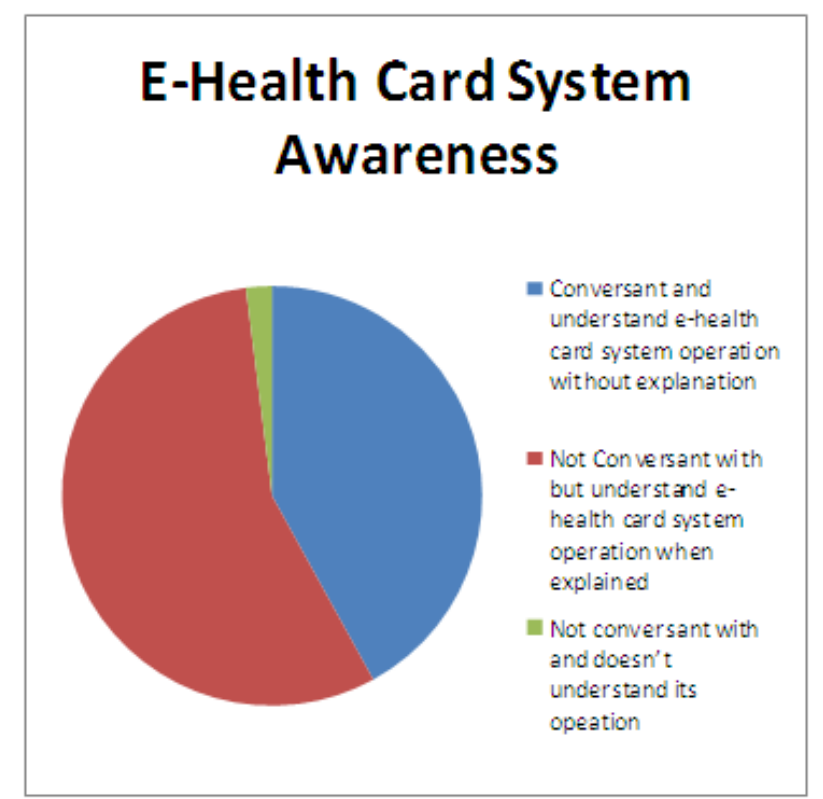

Fig 4: Chart showing Awareness distribution of respondents to E-Health system

Meanwhile, $26 \%$ of survey participants believe doctors will benefit by having patient records stored in an efficient and reliable way, without fear of misrepresentation and loss/damage of patient information, data and history. $51 \%$ believe the system would allow easier and faster access to patient's history record and will also promote understanding and communication relationship between patients and medical practitioners. $40 \%$ are certain that the proposed system would lead to better diagnosis for the patient and rapid administration. $43 \%$ believe that it will present easy accessibility to health services and also low cost of these services. $41 \%$ raised issue on the e-health card security and confidentiality, 23\% argued whether it's appropriate for patients to be given the power to be able to see all their past medical transactions i.e. doctor's diagnosis and prescriptions, citing that it could encourage patient's selftreatment. $34 \%$ support the notion that the proposed system can help to reduce corruption in the health sector. $36 \%$ believe that the proposed system will help check, reduce and control the marketing and prescription of 
illegal drugs. $58 \%$ believe that the proposed system will guarantee ease of access to doctor's prescription by every patient when necessary. $50 \%$ believe that it will help to prevent selling medicines without doctor's prescription.

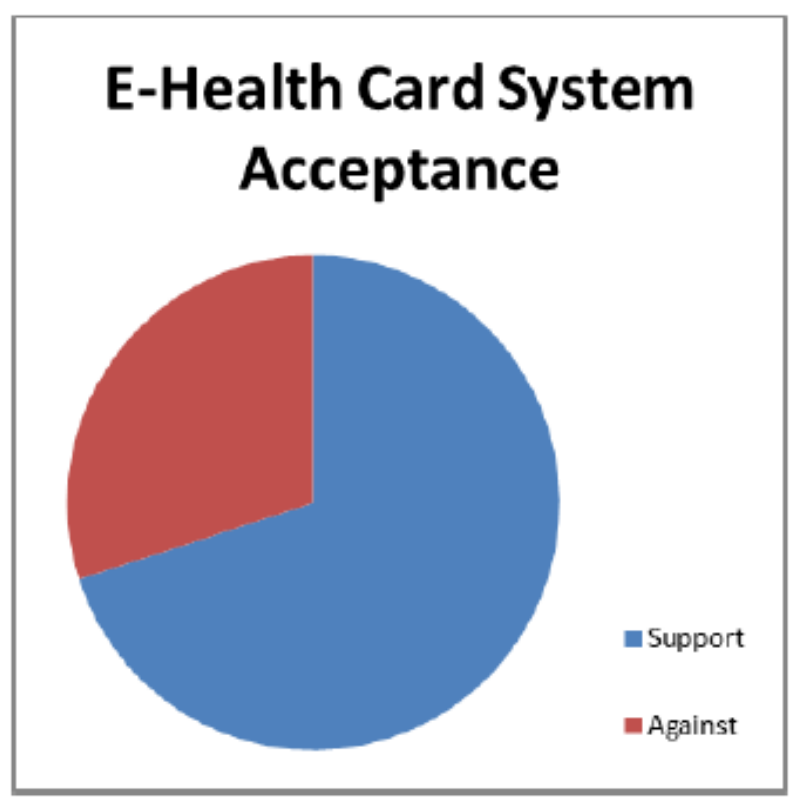

Fig5: Chart showing Acceptance / Rejection distribution of E-Health system

\section{Respondent's Recommendation}

The result of the study had the participants presenting their suggestions as regarding the proposed e-Health card system. Some suggestions were made, these includes

- Proper enlightenment of such scheme should be put in place before actual nationwide implementation; this will dissuade people (especially religion fanatics) from misinterpreting the aim of the scheme. Also, a pilot scheme should be put in place such that the system is launched in those pilot areas first before extending it nationwide. This will allow proper experimentation of the possible problems and challenges of the system.

- Government should improve electricity generation and distribution

- Rural areas should be considered and carried along with the project in terms of affordability, accessibility and literacy.

- Computer literacy should be well encouraged nationwide for the populace.

- Fund and improve the standards of medical infrastructures and equipment to appropriately complement the e-Health system.

- Policies must be formulated for proper management and monitoring.

- There should be no social class discrimination.

- Dwelling on the sheer mobile phone use, such a system should support mobile phones users e.g. patients and Doctors alike should be able to query the central database through mobile phone internet connectivity.
- Government should accelerate provision of broadband internet connectivity in both rural and urban areas. This can be done through fibre optics layout nationwide or setting up a law for mandatory internet provision by all telecoms service provider at all medical facilities in the countries as part of their corporate social responsibility. This will work as GSM telecoms services have spread across the whole country.

- Medical practitioners must be well trained on how to use the system.

- Government must establish monitoring and supervision agency to ensure data validity and communication to the Ministry of Health.

Our survey highlights that Nigeria has the opportunity and willingness for moving forward in the application of ICT in the health care sector albeit with the consideration of the salient issues raised. Even though our research was carried out in a single state of the federation, it is of utmost belief that the statistics can be extended to other parts of the country. Some recommendations highlighted from this work can aid the ministry of health in proper planning, design and implementation of health policies with a view to salvaging the health sector of the country from its continuous deploring state.

\section{CONCLUSIONS}

This study presents a holistic view of the present ehealth adoption and use in Nigeria. We studied the existing health system which lacks the sophistication ICT tools adoption offers. We critically analyzed the cons of the existing system and then motivate the adoption of an e-health platform. In this, we considered the introduction of an e-health card system. We conducted an empirical analysis through a thorough survey both from the locals and professionals alike on their view on e-health adoption and use, reservations and recommendations. In our survey, we selected a state out of the 36 states of the federation for opinion sampling; our choice of state is predicated on the perfect mix the state enjoys of both the rural and urban set up, the literacy level of the citizenry and availability of three (3) University teaching hospitals one each as a private, state and federal government owned. We believe such tertiary health care facilities afford us the rare opportunity of meeting with a large number of the best health practitioners in the country all within small confinement. We have presented statistically the response received from the survey as well as some recommendations on ways of making the system to be more efficient. Our next focus is to model a theoretically sound e-health system for the country; our proposed work will focus on finding the technical deficiencies in some components of e-health system in use and applying gridcomputing as back end for such proposed e-health system, bearing in mind the security features, degree of ICT literacy by citizen, level of infrastructural development and the general technical know-how availability in the country. 


\section{AKNOWLEDGEMENTS}

The authors wish to thank the anonymous reviewers for helping to make this work better. We also thank those who volunteered to fill the research questionnaires and survey questions.

\section{REFERENCES}

[1] Watts, C., \& Ibegbulam, I. (2005). Access to electronic healthcare information resources in developing countries: experiences from the Medical Library, College of Medicine, University of Nigeria.Available:http://72.14.253.104/search?q=cache:wT 53fzH_TXEJ:www.ifla.org/IV/ifla71/papers/164eWatts_Ib egbulam.pdf $+\% 22 \mathrm{ICT}+$ infrastructure $\% 22+$ healthcare $+\% 2$ 2 developing.

[2] WHO. (2006): The global shortage of health workers and its impact. Available: www.who.int/mediacentre/factsheets/fs302/en/index.html.

[3] Nykanen, P.: E-Health Systems: Their Use and Visions for the Future. Tampere University, Finland. Idea Group Inc. 2006.

[4] Eysenbach, G.: What is e-health? [Editorial]. J Med Internet Res, 1(2), 2001.

[5] Silber D: The case for ehealth. European Commission, Information Society, eHealth Conference, Atlanta, Belgium. 2003.

[6] National e-health strategy South Africa 2012. Department of health, republic of South Africa, 2012.

[7] WHO. (2002) the world health report, Geneva, Switzerland..

[8] Denise s.: The case for e-health. 2003 [Available online at: http://www.eipa.nl/Publications/Summaries/03/2003_E_01 .pdf], last accessed on 2013-7-12.

[9] Drury P.: E-Health International: A model for developing countries, 2010. [Available online at: http://unpan1.un.org/intradoc/groups/public/documents/un pan/unpan037263.pdf], last accessed on: 2013-6-27.

[10] Asuzu, M.: The necessity for a health systems reform in Nigeria. Journal of community medicine \&primary health care. 16(1) 1-3, 2012.

[11] Nwangwu, P: Health care delivery in Nigeria: contribution of Nigerians in Diaspora: Address to the convention of Nigerian professionals in Diaspora; Paris, France, 2011.

[12] Trading Economics (2013), Rural Population in Nigeria. [Available online http://www.tradingeconomics.com/nigeria/ruralpopulation-wb-data.html], Last accessed on: 2013-6-23.

[13] Ngozi O., (2013). Overview of the 2013 Budget. [Available online at: http://www.budgetoffice.gov.ng/bof_2013update/CME_Budget_Speech1.pdf], last accessed on: 2013-06-24.

[14] Won J., (2003). Smart Card Technology Capabilities, The National Institute of Standards and Technology (NIST) is an agency of the U.S. Commerce Department. [Available online at: http://csrc.nist.gov/publications/nistir/IR7056/Capabilities/JunSmartCardTech.pdf], Last accessed on: 2013-08-03.

[15] Mohammad A., and Palash C: Introducing an e-Health card for Developing Countries. 2011. [Available online at: http://su.divaportal.org/smash/get/diva2:428633/FULLTEXT01.pdf], Last accessed on: 2013-06-23.
[16] Fraser HSF., Biondich P., Moodley D: Implementing electronic medical record systems in developing countries. 2005 [Available online at: http://groups.csail.mit.edu/medg/ftp/psz/EMR-designpaper.pdf], Last accessed on: 2013-07-26.

[17] GridTalk: Grid Briefings: The Future of Healthcare: eHealth and Grid Computing. 2009. [Available online at: http://www.gridtalk.org/Documents/ehealth.pdf], Last accessed on: 2013-07-24.

[18] World Bank Data (2012), Nigeria |Data. [Available online at: http://www.data.worldbank.org/country/nigeria], Last accessed on: 2013-6-23.

Adebayo Kolawole John, male, Ijebu-Ode, Nigeria, Lectures at Southwestern University Nigeria.

His research directions include Intelligent Systems, ICT adoption and use, Computer Security, Computer Vision and Image Processing.

Engr. Edward Osita Ofoegbu, male, Oduduwa University, IleIfe, Nigeria, Lecturer, Doctoral Student of department of electronic and computer engineering, Nnamdi Azikiwe University, Awka. His research directions include Robotics and control systems. He can be reached at department of Physics Electronics, Oduduwa University, Ile-Ife or on email at edoxnt@yahoo.com. 


\section{APPENDIX}

\section{Research Questionnaire Extract}

\section{E-Health Care assessment and e-Health card adoption in Nigeria}

(Brief Description: An e-Health card is a smart card like an ID card for patients that allow doctors and patients interact over electronic devices such as a PDA (Personal Digital Assistant). The patients' data and medical history is stored in a database that can be accessed online anytime.)

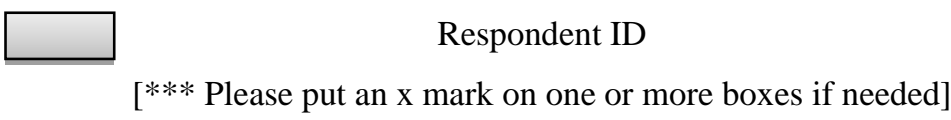

1. Name of the Respondent:

2. Age:

3. Sex: $\square$ Male Fem $\square$

4. Address/Location/Local Govt. Area:

5. Education Level:

6. Occupation:

7. What are the problems of present health care system in Nigeria?

8. What technologies are currently in place that can support e-health solutions?

9. What is the level of access to computer equipment at healthcare centres?

10. Do you have access to internet in your health care facility? How frequent is it being used by staffs?

11. Is your health facility aware of a national electronic health database?

12. Do you have a comprehensive automated Health Information System in your health facility? How often is it used? If it is not often used, what are the impediments? Is it appropriately linked to the national health database? Are all your patients adequately uniquely identified with a national unique health identifier?

13. Do you have competent staffs to man the automated health information system? Are your health professionals comfortable with ICT use?

14. Can you foresee any benefits of ICT applications in rural healthcare centres?

15. Can you describe in general terms, the barriers to ICT applications in healthcare delivery? Can you also state the barriers to ICT use in your own health facility?

16. Do you know about e-Health (electronic health) card?

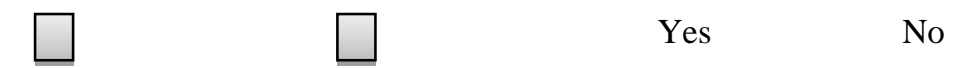

17. If yes, then what are the perceived advantages of e-Health card?

18. Do you think that the proposed e-Health card will be essential nowadays?
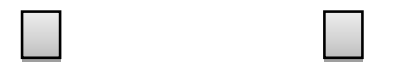
Yes
No

19. Do you think that the proposed e-Health card will be beneficial for both doctors and patients?

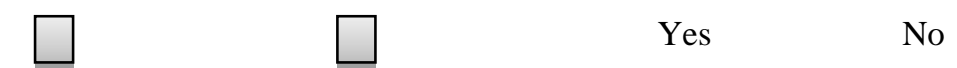

20. If yes, what do you believe are the benefits they can get through the e-Health card?

21. Do you think that it's possible to introduce e-Health care in Nigeria

$\square \quad$ Yes No

22. Do you think that the proposed e-health card will bring about positive changes in the country's healthcare system? 
$\square \quad$ Yes $\quad$ No

23. How can e-Health card contribute to reduce present problems in healthcare system?

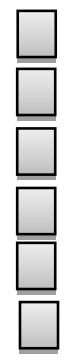

To keep records of patients' data properly and accurately

Proper distribution of medicine for patient

To reduce corruption in health sector

To check, reduce and control marketing of illegal drugs.

Access to doctor's prescription by every individual

To prevent selling medicines without doctor's prescription

24. Do you think that general people will get benefits from using e-Health card?

$\square \quad \square \quad$ Yes No

25. Do you think that the proposed e-Health card technology will ensure the quality of healthcare system throughout the country?

$\square \quad \square \quad$ Yes No

26. Do you think that the Federal Government should introduce an e-Health card for every individual?

$\square \quad$ Yes No

27. What reservations do you have about introducing e-Health card in Nigeria?

28. What are your recommendations on introducing e-Health card in improving e-health care in Nigeria?

29. Do you want to make any additional comment? 